\title{
ТРИБУНА ПРЕПОДАВАТЕЛЯ
}

\author{
Наталья М. Калмыкова ${ }^{1}$ \\ Экономический факультет \\ Московского государственного университета имени М. В. Ломоносова, \\ Российская Федерация, 119991, г. Москва, \\ Ленинские горы, дом 1 , строение 46, \\ https://www.econ.msu.ru
}

\section{ПРИМЕРЫ СЕЛЕКТИВНОСТИ ДЕМОГРАФИЧЕСКИХ ПРОЦЕССОВ В КУРСЕ «ДЕМОГРАФИЯ»}

Аннотация. В статье обсуждается необходимость обращения к понятию селективности демографических процессов в курсе Демографии в бакалавриате, приводятся примеры проявления селективности различных демографических процессов.

Ключевые слова: селективность демографических процессов, эффект здорового мигранта, эффект здорового работника

JEL CODES: J00

Цитирование: Калмыкова Н. М. Примеры селективности демографических процессов в курсе «Демография». Население и экономика. - 2017. - Т. 1. - № 1. - С. 117-121.

Явление, получившее название «систематической ошибки выжившего» (survivor bias), широко известно в экономических исследованиях и обсуждается в ряде экономических курсов на уровне бакалавриата и магистратуры. Например, при изучении деятельности компаний, те из них, которые по разным причинам прекратили работать, не попадают в выборку, что приводит к смещенным, завышенным оценкам результативности деятельности компаний, поскольку показатели компаний-неудачников не были учтены. Селективность находит прикладное применение в страховании, в том числе в личном страховании, когда величина страховой премии связана с возрастом и состоянием здоровья застрахованного.

Д. Хекман (J. Heckman), получивший Нобелевскую премию по экономике в 2000 г. «за разработку теории и методов для анализа селективных выборок», отмечал значимость учета этого феномена и в демографических исследованиях, указывая на то, что «в демографических исследо-

1 Наталья Михайловна Калмыкова, кандидат экономических наук, доцент, доцент кафедры народонаселения экономического факультета МГУ имени М.В.Ломоносова. E-mail: natalia@econ.msu.ru 
ваниях, и в экспериментах по установлению эффективности обучения обычно рассматриваются лишь те единицы наблюдения, данные по которым есть на протяжении всего периода наблюдения. Эти особенности проведения анализа приводят к результатам, схожим с проблемой самоотбора: при оценивании структурных уравнений “смешиваются” основные факторы, представляющие главный интерес, и факторы, определяющие вероятность попадания в выборку» [Хекман, 2013 , с. 130].

Исторически, еще в XVIII в., одним из первых отметил возможность селективности демографических процессов, и в частности - процесса смертности, А. Депарсье (A. Deparcieux). Он рассчитал таблицы смертности для рантье, сравнив их с таблицами смертности всего населения, а также таблицы смертности монахов различных монашеских орденов и пришел к выводу, что смертность рантье ниже, чем смертность всего населения, потому что рантье можно отнести к элите, поведение которой отличается от поведения других людей [Dupâquier, 1996].

В курсах демографии для бакалавриата вопросы селективности демографических процессов затрагиваются крайне редко, эта тема, как правило, отсутствует в программах курсов и в российских вузовских учебниках, что приводит к ошибочным трактовкам студентами известных феноменов. Например, при объяснении снижения возрастных коэффициентов смертности от онкологических заболеваний в старших возрастах (рис. 1) студенты, не знакомые с понятием селективности демографических процессов, склонны объяснять динамику возрастных коэффициентов смертности в старших возрастах просто снижением смертности, без учета состава населения по отношению к смертности от изучаемого класса болезней.

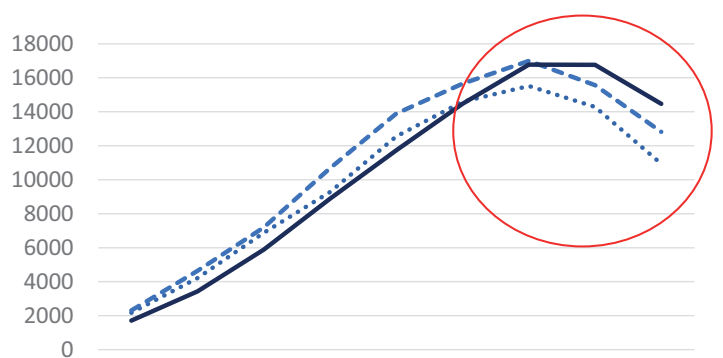

45-49 50-54 55-59 60-64 65-69 70-74 75-79 80-84 85+

$$
\text { ….... } 1984----1994 \longrightarrow 2004
$$

Рис. 1. Возрастные коэффициенты смертности от новообразований (коды МКБ-10: C002-D48), на 1 млн человек, Россия, мужчины

Источник: Human Cause-of-Death Database. French Institute for Demographic Studies (France) and Max Planck Institute for Demographic Research (Germany): www.causeofdeath.org (дата обращения: 15.11.2017) 
Другой пример пренебрежения селекцией - оценка итоговой рождаемости или брачности поколений по данным переписи населения на основе, например, опроса женшин, вышедших за границы репродуктивного возраста $(50+)$. При этом за пределами внимания исследователя остаются те женщины, которых не опросили в ходе переписи либо потому, что они сменили место жительства, либо потому, что они не дожили до переписи. Поскольку нам не известно априори, были ли те женщины, которых не опросили в переписи, особой (селективной) группой по отношению к рождаемости или брачности, т.е. отличались ли характеристики их рождаемости (например, среднее число рожденных детей) или брачности (средний возраст вступления в брак) от тех же характеристик среди опрошенного населения, мы не можем с уверенностью утверждать, что рассчитанные на основе данных переписи показатели рождаемости и брачности можно считать несмещенными оценками этих процессов в когортах женщин.

Если состав когорты (населения) неоднороден по отношению к риску наступления изучаемого события, то с частью индивидов, у которых вероятность наступления события выше, оно случится раньше, чем с остальными. Либо с остальными индивидами оно не случится вообще (если речь идет о конкурирующих рисках). В нашем примере (см. рис. 1) в старших возрастах снижение возрастных коэффициентов смертности от новообразований связано не со снижением смертности от этой причины вообще, а с постепенным исчезновением в изучаемом населении людей, умирающих от этой причины в более ранних возрастах либо умирающих от других причин. Таким образом, в основе селективности лежит гетерогенность населения по отношению к изучаемому феномену.

В демографической литературе описаны различные проявления селекции. Приведем несколько примеров.

«Эффект здорового работника» (healthy worker effect) рассматривался в статье, посвященной анализу смертности занятых в химической промышленности в США) [Burns, Bodner, Jammer, Collins, Swaen, 2011]. Эффект состоит в том, что здоровье работников, занятых на предприятиях с вредными условиями труда, может оказаться лучше, чем у населения страны в целом. Результаты исследования показали, что занятые в химической промышленности (от чернорабочих до руководства компаний) имеют более низкие стандартизованные по возрасту коэффициенты смертности от незлокачественных заболеваний, что объясняется несколькими факторами, и в том числе селекцией, благодаря которой нанимаются более здоровые работники и увольняются работники со слабым здоровьем. «Эффект здоровья при найме» (healthy hire effect) действует с двух сторон: работника и нанимателя. Например, кандидата со слабым здоровьем или с ожирением не примут на работу, требующую физических усилий или высокой мобиль- 
ности; кандидат с астмой не пойдет устраиваться на предприятие с плохим качеством воздуха; курящие могут отказаться от устройства на работу, если работодатель запрещает курение, и т.п. Здоровье работников может оказаться лучше также благодаря существующим в компании с вредными условиями труда дополнительным программам страхования здоровья.

«Эффект здорового мигранта» (healthy migrant effect) [Bershete, Jusot, 2010] - парадокс, согласно которому мигранты оказываются более здоровыми, с низкими показателями заболеваемости и смертности по сравнению с постоянным населением страны. Этот парадокс обычно объясняют селективностью миграции, «отбирающей» индивидов с лучшим здоровьем. Другое проявление селективности миграции получило название «эффект лосося» (salmon bias). Он также объясняет лучшее здоровье мигрантов, но не отбором «на въезде», а, напротив, тем, что пожилые мигранты возвращаются в страну выхода, в результате их смерти регистрируются на родине, уменьшая числитель коэффициентов смертности и заболеваемости. Третье проявление селективности миграции, на которое указано в статье, состоит в различии социокультурных традиций по отношению к курению, потреблению алкоголя, привычкам питания между мигрантами и населением страны приёма.

Как показало исследование [Preston, Elo, 2014], «эффект здорового мигранта» лежит в основе разницы между уровнем продолжительности жизни при рождении населения Нью-Йорка и США в целом. Если не принимать во внимание селективность миграции, то весьма трудно объяснить увеличение разницы в продолжительности жизни ньюйоркцев и населения США в целом: за 20-летний период с 1990 по 2010 г. ожидаемая продолжительность жизни мужчин выросла на 10,49 года в Нью-Йорке и только на 4,49 в США в целом. У женщин в Нью-Йорке продолжительность жизни увеличилась на 6,25 года, а в стране в целом - на 2,39 года. При этом рост продолжительности жизни в городе шел на фоне роста бедности, снижения доходов домохозяйств, ухудшения образовательной структуры населения. Авторы статьи приходят к выводу, что в основе различий в темпах роста продолжительности жизни лежит структура населения по месту рождения: при близких уровнях продолжительности жизни населения, родившегося в США и за границей, доля родившихся за границей в Нью-Йорке существенно выше, чем в США. В 2008-2010 гг. продолжительность жизни мужчин, родившихся в США, составила в стране в целом 75,38 года, в Нью-Йорке - 75,28 года, а мужчин, родившихся за границей, - 81,18 и 81,06 соответственно. Доля родившихся за границей в населении США при этом составила 13,6\%, в населении НьюЙорка - 37,8\%. И поскольку продолжительность жизни у этой части населения выше, то и общая продолжительность жизни в городе выше, несмотря на ухудшение социально-экономических условий. Более низкая 
смертность мигрантов по сравнению со всем населением объясняется авторами «эффектом здорового мигранта»: худший доступ мигрантов к медицинскому страхованию и процедурам медицинского скрининга компенсируется поведенческими факторами - мигранты реже курят, реже потребляют алкоголь и страдают ожирением, распространенность ВИЧинфицирования среди них также ниже. Таким образом, принимая во внимание селективность миграции, авторы делают вывод о том, что ведущую роль в росте продолжительности жизни в Нью-Йорке сыграло не улучшение работы системы здравоохранения, а изменение структуры населения по месту рождения.

При расчете показателей интенсивности демографических процессов в чистом виде, т.е. когда рассматривается только один процесс, возможность селекции не учитывается. Как правило, принимается так называемое условие независимости (condition of independency), введенное в научный оборот французским демографом Луи Анри (L. Henry) [Henry, 1966]. Если же рассматривается совместное действие двух или нескольких процессов, часто селекцией пренебречь невозможно. При наличии селекции необходимо ее корректировать, разделив население на однородные подгруппы по отношению к изучаемому процессу (см., например, [Wunsch, Termote, 1978]).

\section{Список используемой литературы}

1. Хекман Д. Смещение селективной выборки как ошибка спецификации // Прикладная эконометрика. 2013. № 31(3). С. 128-137: http://pe.cemi.rssi. ru/pe_2013_3_129-137.pdf (дата обращения: 19.11.2017).

2. Bershete C., Jusot F. L'état de santé des migrants de première et de seconde génération en France. Une analyse selon le genre et l'origine // Revue économique. 2010. No. 61(6). Pp. 1075-1098. Doi: 10.3917/reco.616.1075.

3. Burns C. J., Bodner K. M., Jammer B. L., Collins J. J., Swaen G. // Occupational medecine. 2011. No. 61(1): https://academic.oup.com/occmed/article/61/1/40/1450389 (дата обращения: 11.10.2017)

4. Dupâquier J. L'invention de la table de mortalité. Paris: PUF, 1996.

5. Henry L. Analyse et mesure des phénomènes démographiques par cohortes // Population. 1966. No. 21(3). Pp. 465-482.

6. Preston S. H., Elo I. T. Anatomy of a Municipal Triumph: New-York City's Upsurge in Life Expectancy // Population add Development Review. 2014. No. 40(1). Pp. 1-29.

7. Wunsch G. J., Termote M. G. Introduction to Demographic Analysis. New York, London: Plenum Press, 1978. 